\title{
Epigenetic responses to abiotic stresses during reproductive development in cereals
}

\author{
Kevin Begcy ${ }^{1}$ (D) Thomas Dresselhaus ${ }^{1}$ (D)
}

Received: 6 January 2018 / Accepted: 22 June 2018 / Published online: 26 June 2018

(c) The Author(s) 2018

\begin{abstract}
Key message Overview of current understanding of epigenetic alterations after abiotic stresses during reproductive development in cereals.

Abstract Abiotic stresses, including heat, drought, cold, flooding, and salinity, negatively impact crop productivity. Various stages during reproductive development are especially sensitive to environmental stresses, which may lead to complete sterility and severe yield losses. Plants exhibit diverse responses to ameliorate stress damage. Changes in DNA methylation, histone modification as well as regulation of small RNA and long noncoding RNA pathways have been shown to represent key modulators in plant stress responses. During reproductive development in cereals, various protein complexes controlling histone and DNA methylation have been identified, revealing conserved and novel mechanisms regulating abiotic stress responses in cereals and other plant species. New findings highlight the role of transposable elements during stress periods. Here, we review our current understanding of epigenetic stress responses during male and female gametophyte formation (germline development), fertilization, early seed devolvement, and seed maturation in cereals. An integrative model of epigenetic responses during reproductive development in cereals is proposed, emphasizing the role of DNA methylation and histone modifications during abiotic stresses.
\end{abstract}

Keywords Abiotic stress $\cdot$ Germline $\cdot$ Fertilization $\cdot$ Seed development $\cdot$ DNA methylation $\cdot$ Histone modification $\cdot$ Small RNAs $\cdot$ Maize $\cdot$ Rice $\cdot$ Wheat

\section{Introduction}

With the human population continuously growing, the demand for food supply is increasing exponentially. Unfortunately, production of cereal grains, including some of the most important crops such as maize, wheat, rice, barley, rye, and oats, is highly vulnerable to abiotic stresses (Barnabas et al. 2008; Begcy and Walia 2015a, b; Chen et al. 2016; Ejaz and von Korff 2017; Folsom et al. 2014) and thus severely threatens the production of sufficient food for human and animal consumption. Abiotic stresses, such as cold, heat,

Communicated by Dolf Weijers.

Kevin Begcy

kevin.begcy@ur.de

Thomas Dresselhaus

thomas.dresselhaus@ur.de

1 Cell Biology and Plant Biochemistry, Biochemie-Zentrum Regensburg, University of Regensburg, 93053 Regensburg, Germany salinity, drought, and flooding, which are associated with global climate change, negatively affect plant growth and development and thus represent a major obstacle for sufficient crop production. Reproductive development is especially sensitive to certain stresses, which may cause sterility and losses in grain yield, directly impacting productivity.

Cereals have developed different mechanisms to survive to both constantly changing and extreme environmental conditions (Barnabas et al. 2008; Bartels and Sunkar 2005; Basu et al. 2016; Begcy et al. 2011; Fahad et al. 2017; Mattiello et al. 2014). However, the responses of cereals to environmental stresses largely depend on their specific developmental stage. For instance, common responses during vegetative development include reduced light perception and perturbations in processes associated with carbon assimilation and transpiration (Barnabas et al. 2008). On the other hand, during reproductive development more detrimental responses are observed including male and female gametophyte malformation, sterility, seed abortion, as well as shortening of developmental phases and transitions. In contrast to vegetative development, in which stress periods can be tolerated 
to a certain extent, if stresses occur at critical stages during reproductive development such as male and female gametophyte formation (germline development), fertilization, early seed devolvement, and seed maturation, negative effects in grain yield are commonly observed.

Reproductive development begins with the formation of flowers. This process, which includes the transition of vegetative to flower meristems, and which is strongly influenced by environmental factors, has been nicely reviewed elsewhere (e.g., Hyun et al. 2017) and, therefore, is not the focus of this review. Therefore, here we are discussing the successive reproductive stages in cereals. Inside flower organs, male gametophytes (pollen) and female gametophytes (embryo sacs) are produced in anthers and ovules, respectively. While in most cereals (i.e., in rice, wheat, and barley) ovary and anthers are located in the same flower, species such as maize generate male flowers containing anthers as an apical tassel inflorescence and female flowers containing ovaries from axillary meristems forming cobs. During the processes of micro- and megasporogenesis including meiosis as well as micro- and megagametogenesis, both male and female gametophytes form gametes. In cereals, like in many other flowering plant species, pollen at the mature tri-cellular stage contains two sperm cells, while the embryo sac harbors a haploid egg and a di-haploid central cell (Zhou et al. 2017). After maturity, pollen grains are released from anthers and transferred to the stigma consisting of multicellular papilla hairs. Pollen grains adhere, hydrate, germinate, and penetrate into papilla hairs to grow toward one of the two transmitting tracts. Transmitting tracts serve as highways toward the ovule and ultimately guide pollen tubes toward the micropylar region of the female gametophyte (Lausser et al. 2010). Short-range guidance is necessary to lure the pollen tube toward the egg apparatus (egg cell and two synergid cells). After reaching its final destination, two sperm cells are released. One of the sperm cells fuses with the egg cell and the other one fuses with the central cell to produce the embryo and the endosperm, respectively (Bleckmann et al. 2014). These coordinated and well-established processes are altered or disrupted when plants are submitted to abiotic stresses.

Recent evidences propose that DNA methylation-, histone modification-, small regulatory RNA (sRNA)- and long noncoding RNA (lncRNA)-associated regulatory pathways are affected during plant development under stress conditions. These include stages of reproductive development such as gametogenesis and seed development (Begcy and Walia 2015a, b; Chen et al. 2016; Folsom et al. 2014; Zemach et al. 2010). In cereal reproductive development, it was shown that DNA methylation is a fundamental step for transcriptional repression of transposable elements (TEs) and regulation of gene expression (Huh et al. 2007; Zemach et al. 2010), a mechanism well described during vegetative development in other plant species. DNA methylation occurs at cytosine residues within three different sequence contexts $(\mathrm{CG}, \mathrm{CHG}$, and $\mathrm{CHH}$ ). While methylation at $\mathrm{CHG}$ and $\mathrm{CHH}$ sites is predominantly found in TEs, CG methylation occurs in TEs and protein-encoding genes (Cui and Cao 2014; He et al. 2010; Lanciano and Mirouze 2017; Pikaard and Mittelsten Scheid 2014; Xia et al. 2017; Zemach et al. 2010). Chromatin marks and chromatin modifying enzymes also play a critical role by regulating gene expression under both optimal and sub-optimal conditions. The central unit of chromatin is the nucleosome, which is formed by an octamer of four core histones (H2A, H2B, H3, and H4, wrapped by 147 base pairs of DNA. Histone N-terminal tails are essential for their regulation, since a large number and type of modified residues are located in this region (Asensi-Fabado et al. 2017; Kouzarides 2007). In cereals as well as in other plant species, histone modifications at these sites including methylation, acetylation, phosphorylation, ubiquitination, and SUMOylation are the most studied. Different residues, typically mono-, di- and tri-methylated lysines and arginines, are best characterized. Tri-methylation of lysine 27 of histone 3 (H3K27me3) was shown to be generally associated with a repressive chromatin state and has been shown to be crucial for vernalization in cereals and other plants (Dennis and Peacock 2009; Diallo et al. 2012; Oliver et al. 2009). Another histone tail modification, tri-methylation of lysine 4 of histone 3 (H3K4me3), correlates with gene activation in cereals (Dong and Weng 2013; Liu et al. 2015), similarly as observed in other animal and plant species. Chromatin modulators such as small RNA-related pathways (siRNAs and miRNAs), which act directly on chromatin and induce RNA-dependent DNA methylation (RdDM), have also been described (Lanciano and Mirouze 2017). In plants, sRNAs are classified into several major classes, including microRNAs (miRNAs), Piwi-interacting RNAs (piRNAs), small interfering RNAs (siRNAs), which enclose phased and secondary interfering RNAs (phasiRNAs), small nucleolar RNAs (snoRNAs), tRNA-derived small RNAs (tsRNAs), small rDNA-derived RNA (srRNAs), and small nuclear RNA (U-RNAs) (Asensi-Fabado et al. 2017; Fei et al. 2013). Among these, miRNAs generated from dsRNA regions of hairpin-shaped precursors, and siRNAs, including phasiRNAs, originating from long dsRNAs (Asensi-Fabado et al. 2017; Fei et al. 2013; Kouzarides 2007), are the best studied in cereals and other plant species. How these pathways control reproductive development in cereals and how they ultimately respond to reduce stress effects and still generate seeds, is a major topic of this review.

During reproductive development, most epigenetic studies have been conducted at well-defined and discrete stages. Here, we are focusing on three developmental stages during reproductive development and how they are affected by environmental stresses. First, we describe (1) epigenetic 
alterations during pre-fertilization processes (male and female gametogenesis). Then, we discuss (2) fertilization mechanisms, gamete activation, and early seed development involving pro-embryo and syncytium formation as well as endosperm cellularization. Finally, we cover a stage known as (3) seed maturation, in which starch accumulation, desiccation, and seed dormancy are major processes taking place. Even though reproductive development can be subdivided into several other stages, recent reports have shown the importance of the aforementioned stages or phases as determinant for productivity in cereals (Begcy and Walia 2015a, b; Chen et al. 2016; Folsom et al. 2014; He et al. 2015; Lamaoui et al. 2018; Muller and Rieu 2016; Parihar et al. 2015; Sabelli 2012; Sade et al. 2018), especially when exposed to abiotic stresses. We highlight recent advances and provide an integrated model of epigenetic regulation incorporating the main key players controlling reproductive development described so far in cereals under abiotic stresses.

\section{Abiotic stresses affect pollen development}

Pollen formation is a major aspect of plant reproduction. Several genes and epigenetic factors controlling cell fate during gametophyte formation have been described in cereals. Male germline development in maize is regulated by the glutaredoxin gene male sterile converted anther 1 (MSCA1), which promotes male germline cell fate and meristem growth (Chaubal et al. 2003). Moreover, it was shown that during stress-associated hypoxia, a common condition in rice fields due to flooding, low levels of oxygen stimulate the increase in germ cell numbers, thus promoting ectopic formation of germ cells in the epidermal layer. Conversely, oxidizing environments inhibit germ cell specification and cause ectopic differentiation in deeper tissues as well as a reduction in archesporial cell number, which are progenitors of the germline (Kelliher and Walbot 2012). In the mscal mutant 24-nt phased small interfering RNAs (phasiRNAs) were lacking, suggesting that stress-induced mis-regulation of MSCA 1 causes the absence of phasiRNAs in anthers and thus affects a number of unknown target genes (Zhai et al. 2015). Another key regulator during male germline development, that is oxygen dependent, is multiple archesporial cells 1 (MAC1). When MACl is expressed, a small protein is generated that induces adjacent cells to differentiate into supportive tissues (Wang et al. 2012). Anthers submitted to heat stress in barley (Hordeum vulgare) showed gradual degeneration of epidermal and archesporial cells resulting in anther abortion as a consequence of transcriptional inhibition (Abiko et al. 2005). Reduced MACl expression might be a cause for this observation. However, it seems possible that MACl is regulated by chromatin modifications (Table 1).
During male gametophyte formation in rice, it was reported that transition of pollen mother cells (PMCs) from pre-meiosis to meiosis stage is controlled by an increase in di-methylation of lysine 9 of histone 3 (H3K9me2) and a decrease in acetylation of lysine 9 of histone 3 (H3K9) as well as phosphorylation of histone 3 (H3S10) (Liu and Nonomura 2016). These well-coordinated epigenetic events regulate Meiosis Arrested At Leptotene 1 (MEL1), which encodes a germline-specific AGO protein that preferentially binds 21-nt phasiRNAs derived generally from intergenic regions. Additionally, MEL1 plays a central role in the progression of meiosis beyond the leptotene stage (Komiya et al. 2014). Rice mell mutants show abnormal tapetum and aberrant vacuolation of microspore mother cells impeding chromosome condensation during early meiosis, thus causing male sterility (Nonomura et al. 2007). This indicates that accumulation of 21-nt phasiRNAs induces male sterility. Moreover, new reports identified IncRNAs, which are successively processed into sRNAs as main regulators of male sterility in rice (Ding et al. 2012). It was further supported that alterations in photoperiod and temperatures cause single spontaneous mutations in sRNAs leading to male sterility in rice (Fan and Zhang 2018; Zhou et al. 2012).

In maize, phasiRNA biogenesis shows a high level of spatiotemporal dynamics throughout anther development (Zhai et al. 2015) with preferential accumulation of 21-nt phasiRNAs during pre-meiosis and 24-nt phasiRNAs during meiosis. The latter persist during pollen formation. Additionally, a stage-specific study in maize anthers at meiosis stage, particularly during zygotene, also reported abundant 21- and 24-nt phasiRNAs as well as two novel miRNAs, zma-MIR11969 and zma-MIR11970 (Dukowic-Schulze et al. 2016). Remarkably, higher levels of DNA methylation at phasiRNAs loci were found especially in the $\mathrm{CHH}$ context indicating a putative role of phasiRNAs in cis-DNA methylation. Targets for 24-nt phasiRNAs have not yet been identified during pollen development. However, in maize Argonaute ( $\mathrm{ZmAGO18b)}$ ) was pointed out as a possible candidate based on its transcriptional profile (Fei et al. 2016). Further experimental evidence is required to confirm this finding. During heat and oxidative stress, wheat phasiRNAs and sRNAs were reported to be highly up-regulated (Wang et al. 2016). Since phasiRNAs and other sRNAs regulate male gametophyte development, it was suggested that their mis-regulation due to increased temperatures and the presence of other stresses such as drought causes pollen malformation. This is commonly observed in mutants of genes controlled by sRNAs as well as under abiotic stress conditions.

In drought-stressed wheat plants, it has been shown that increased abscisic acid (ABA) concentration in pollen grains correlates well with pollen sterility and decreased yield (Ji et al. 2011; Parish et al. 2012). Notably, ABA was also significantly higher in rice florets exposed to heat stress (Tang 
Table 1 Genes regulated in response to abiotic stress during reproductive development in cereals

\begin{tabular}{|c|c|c|}
\hline Epigenetic mechanisms & Genes affected & References \\
\hline \multicolumn{3}{|l|}{ Male gametogenesis } \\
\hline phasiRNAs & Male sterile converted anther 1 (MSCA1) & $\begin{array}{l}\text { Chaubal et al. (2003), Kelliher and Walbot } \\
\text { (2012) }\end{array}$ \\
\hline H3K9me2/H3k9ac/H3S10phos/phasiRNAs & Meiosis Arrested at Leptotene $1(M E L 1)$ & Ding et al. (2012), Komiya et al. (2014) \\
\hline $\mathrm{H} 2 \mathrm{~A}$ phosphorylation & Bub1-related kinase $1(B R K 1)$ & Wang et al. (2012) \\
\hline miRNAs & Suppressor of $\mathrm{G}_{2}$ allele of skp1 (SGT1) & Liu et al. (2017) \\
\hline \multicolumn{3}{|l|}{ Female gametogenesis } \\
\hline DNA methylation; histone acetylation & ABA-related genes & Tang et al. (2008), (2014) \\
\hline DNA methylation & DNA methyltransferases $(D M T s)$ & Zhuang et al. (2008) \\
\hline \multicolumn{3}{|l|}{ Early seed development } \\
\hline H3K4me3/H3K27me3 & Polycomb repressive complex $2(P R C 2)$ & Folsom et al. (2014) \\
\hline DNA methylation & MADS-box protein (MADS87) & Folsom et al. (2014), Chen et al. (2016) \\
\hline DNA methylation & MADS-box protein (MADS69) & Folsom et al. (2014), Chen et al. (2016) \\
\hline DNA methylation & MADS-box protein $(A G L 36)$ & Folsom et al. (2014), Chen et al. (2016) \\
\hline H3K4me3 & Alcohol dehydrogenase $(A D H)$ & Tsuji et al. (2006) \\
\hline DNA methylation & $\begin{array}{l}\text { PINFORMED1-mediated transport of auxin } \\
(P I N 1)\end{array}$ & Zhao et al. (2017) \\
\hline DNA methylation & $\begin{array}{l}\text { Miniature inverted-repeat transposable elements } \\
(\text { MITEs })\end{array}$ & Li et al. (2014) \\
\hline \multicolumn{3}{|l|}{ Seed maturation } \\
\hline DNA methylation & ABA- and GA-related genes & Begcy and Walia (2015a, b), Xing et al. (2015) \\
\hline DNA methylation & Demeter $(D M E)$ & Kapazoglou et al. (2013) \\
\hline Histone acetylation & ADP-glucose pyrophosphorylase (AGPS2) & Zhao et al. (2014), Wang et al. (2017) \\
\hline DNA methylation & Protein phosphatase $2 \mathrm{C}(P P 2 C)$ & Liu et al. (2015), Yu et al. (2016) \\
\hline DNA methylation & SNF1-related protein kinase $2(S N F 1)$ & Liu et al. (2015), Yu et al. (2016) \\
\hline DNA methylation & ABA insensitive 5 ( $A B I 5)$ & Liu et al. (2015), Yu et al. (2016) \\
\hline DNA methylation & Lipid phosphate phosphatase $2(L P P 2)$ & Liu et al. (2015), Yu et al. (2016) \\
\hline DNA methylation & Auxin response factor $(A R F)$ & Liu et al. (2015), Yu et al. (2016) \\
\hline
\end{tabular}

Four major reproductive processes are distinguished. The underlying epigenetic mechanisms, affected genes, and corresponding references are indicated

et al. 2008), indicating that an overall increase in ABA in reproductive tissues has negative effects in plant reproduction. In rice plants drought-stressed during the pollen meiosis stage, hormone pathways related to gibberellic acid signaling and abscisic acid catabolism were shown to be reprogrammed (Jin et al. 2013). Nevertheless, detailed hormonal analyses linked with transcriptomic and epigenetic studies are needed to shed light on the role of ABA and other hormones in reproductive tissues exposed to abiotic stresses. Recently, an interesting approach integrating genome-wide sRNA analysis with quantitative trait locus (QTL) mapping in rice identified four major QTLs for heat tolerance during flowering ( $q H T-3, q H T-6, q H T-8$, and $q H T-12)$. A detailed analysis of QTLs revealed the presence of miRNA targets associated with ABA-responsive genes. Additionally, suppressor of the $\mathrm{G}_{2}$ allele of $\operatorname{skpl}$ (SGT1), a direct target of miRNA166e, was also mapped within the $q H T-8$ locus (Liu et al. 2017). SGT1 has been pointed out as a positive regulator of thermal responses by interacting with heat shock protein (HSP) 90 and HSP70 (Gorovits and Czosnek 2017; Park and Seo 2015). These findings suggest the existence of an integrative mechanism of miRNAs and their targets on modulating abiotic stress responses during anther and pollen development. Finally, even though recent reports have highlighted the role of DNA methylation and sRNAs including phasiRNAs and miRNAs during abiotic stress responses on male germline development, further research addressing the role of other sRNAs and chromatin remodeler genes is needed.

\section{Abiotic stresses during embryo sac development}

Although the impact of abiotic stresses on female gametophyte development has been noticed since decades, due to their inaccessibility, little is known about how stresses impact this important developmental tissue. Water deficit 
induced an increase in the number of antipodal cells in the maize embryo sac, while the growth and receptivity of the style were inhibited (Ribaut et al. 2009). Additional observations pointed toward a significant delay in female organ development of drought-stressed maize plants (Damptey and Aspinall 1976; Damptey et al. 1978). Elevated ABA concentration in ovaries was suggested as the main cause of induction of female flower abortion in stressed plants (Asch et al. 2001). The role of ABA in mediating gene expression changes in response to abiotic stresses is well known (Chinnusamy et al. 2008; Hyun et al. 2017; Wong et al. 2017). In rice, histone deacetylation was observed in plants submitted to cold, mannitol, and salt stress, resulting in repression of ABA regulatory genes. Histone deacetylation imposes a non-permissive chromatin conformation leading to transcriptional repression (Fu et al. 2007). Interestingly, drought stress induced a raise in the ABA concentration in developing ovules of maize and wheat (Andersen et al. 2002; Ji et al. 2011; Kakumanu et al. 2012). This has been suggested to impair cell division, potentially affecting fertilization and further seed formation (Yang et al. 2001). A recent study analyzing whole-genome DNA methylation in rice female gametes (egg and central cell) indicates that under nonstress conditions both cell types display similar methylation patterns compared to other tissues (Park et al. 2016). Whether this pattern changes during stress application has not been investigated. A decrease in global methylation has been reported under stress conditions in rice and ryegrass (Karan et al. 2012; Tang et al. 2014). It was suggested that elevated ABA concentrations reported in earlier studies could possibly be the result of reduced DNA methylation of hormone-related genes. However, these could also be an indirect effect, since new findings in Arabidopsis suggest a low correlation between changes in DNA methylation and transcriptional regulation (Kawakatsu et al. 2016; Meng et al. 2016).

\section{Do abiotic stresses influence fertilization mechanisms?}

Before fertilization is executed in cereals, pollen grains are deposited by wind or animals at papilla hairs of feathery stigmata (silks in maize) where they germinate and grow toward the ovule to deliver its sperm cell cargo. To which extent this so-called progamic phase of reproduction is affected by abiotic stresses is almost completely unclear. A comparison between pre- and post-pollinated silks in maize identified 30 conserved miRNA families (Li et al. 2013). Notably, all families have been associated previously with stress responses. For instance, miR169, miR171, miR393, miR395, and miR528 have been correlated with drought and salt stress responses (Ferreira et al. 2017; Zhao et al. 2009). These findings indicate that pollination and stress-related processes are closely associated and might be genetically regulated by similar epigenetic mechanisms. After sperm cell release, gametes are activated, fusion between the two sperm cells and female gametes takes place, and both embryo and endosperm development stages are initiated (Dresselhaus et al. 2016). Whether these processes, which occur deeply embedded and protected within the maternal tissues of both ovule and ovary, are affected by stress factors, is not known. At present, we understand little about these events under non-stress conditions. It has been controversially discussed whether gene expression in both embryo and endosperm is largely maternal in origin until three to four days after fertilization. It was further suggested that this is epigenetically regulated (e.g., Baroux and Grossniklaus 2015; Grimanelli et al. 2005; Nodine and Bartel 2012; Zhao et al. 2017; Zhao and Sun 2015). However, recent evidence using genome-wide transcriptional analysis in maize and rice revealed that zygotic genome activation occurs soon after fertilization, exhibiting a highly dynamic and partially transient pattern of gene expression (Chen et al. 2017; Anderson et al. 2017). These include genes involved in hormone biosynthesis and responses, RdDM, and other pathways associated with massive chromatin changes after fertilization. Upon fertilization, for example, several genes encoding histone $\mathrm{H} 3$ variants, that are expressed at low levels in male and female gametes, are activated $12 \mathrm{~h}$ after fertilization together with $\mathrm{H} 1$, whose transcripts are absent in sperm cells (Chen et al. 2017). Overall, these patterns indicate that fertilization and early seed development might be very vulnerable to abiotic stresses, but this remains to be demonstrated.

Under heat stress, a strong reduction in fertility was observed when male and female gametes were stressed prior to fertilization. In contrast, cold-stressed gametes did not show significant differences in fertilization rates (Dupuis and Dumas 1990). These observations suggested that high temperatures impose a strong pressure on fertilization. For instance, increased temperatures can decrease the time in which female reproductive structures such as feathery stigmata of cereals are more receptive to pollen, thereby reducing the chances for a successful fertilization. In maize, pollen-stigma interaction and early kernel development were dramatically affected by heat stress, resulting in a significant reduction in kernel formation (Mitchell and Petolino 1988). Further systematic research approaches are required to investigate the molecular mechanisms affected and to distinguish between fertility effects caused by defective gametophytes/gametes or processes directly affecting fertilization-related processes. 


\section{Abiotic stresses strongly affect early seed development}

Early seed development is a highly organized and synchronized genetic process that leads to the formation of both the embryo and the endosperm. In contrast to dicotyledonous plants, where little remnants of endosperm are present at seed maturity, a persistent endosperm in cereals stores starch and proteins required for seedling growth during germination (Hands et al. 2012). Although mature seeds of dicotyledonous and monocotyledonous plants are different regarding complexity of embryo development and endosperm content, initial events during early seed development appear partly similar (Sabelli 2012). Abiotic stresses during early seed development are major limiting factors for cereals production (Begcy and Walia 2015a, b; Chen et al. 2016; Folsom et al. 2014; Hyun et al. 2017). During stress conditions at this specific reproductive stage, cereals exhibit limited endosperm proliferation affecting final seed size (Fujita et al. 2013; Kapazoglou et al. 2010; Li et al. 2015; Luhua et al. 2013). For instance, heat- and drought-induced losses in barley and wheat have contributed to approximately a $60 \%$ decrease in grain weight as well as in seed size (Begcy and Walia 2015a, b; Ejaz and von Korff 2017). Particularly, environmental stresses delay developmental transition from syncytial to cellularization stage of endosperm development. Coincidently with reduced seed size and delayed endosperm development, a subset of genes associated with cell cycle, chromatin assembly, cytoskeleton- and microtubule-related processes as well as hormone balance have been recurrently found as being differentially regulated by environmental stresses during seed development (Begcy and Walia 2015a, b). Concomitantly, reduced protein levels of these genes have been reported under stress conditions (Kesten et al. 2017; Zhang et al. 2017). Mutations and overexpression of some of the genes resulted in a delay or failure of transition toward cellularized endosperm (Dante et al. 2014; Yi et al. 2011).

At the epigenetic level, it was shown that polycomb repressive complex 2 (PRC2) represents a major regulator of early seed development. During endosperm development in cereals, several active members of PRC2 have been identified (Kapazoglou et al. 2010; Tonosaki and Kinoshita 2015). Depending on protein sub-unit combinations of PRC2, several distinct roles have been attributed during seed formation. In barley, two members of the PRC2 complex, fertilization-independent endosperm (FIE) and enhancer of zeste $(\mathrm{E}(\mathrm{z}))$, were shown to affect seed size by regulating endosperm development (Kapazoglou et al. 2013). In rice, repression of FIE1 resulted in abnormal endosperm formation, strongly supporting the idea that PRC2 regulates endosperm development in cereals through DNA methylation and histone modifications, similar to findings in the model plant Arabidopsis. Rice plants submitted to heat stress during early seed development had a significant reduction in seed size (Folsom et al. 2014). This decrease was correlated with mis-regulation of FIEI expression levels. In cereals, FIEI is the only member of the PRC2 complex described so far with an endospermspecific expression pattern (Folsom et al. 2014; Kapazoglou et al. 2010; Tonosaki and Kinoshita 2015). The FIE1 promoter is methylated in the sperm cell, but not in the central cell. After fertilization, an asymmetric pattern of parental DNA methylation is inherited by the endosperm in cereals and other plants. Paternally derived FIEI is silenced, while maternally derived alleles are expressed. However, after heat stress both paternal and maternal FIEI alleles are strongly repressed during early seed development (Chen et al. 2016; Folsom et al. 2014). Together with FIE1 several MADS-box genes including OSMADS87, OsMADS69 and OsAGL36 were mis-regulated in heatstressed rice seeds, which led to a decrease in yield (Chen et al. 2016; Folsom et al. 2014). In barley, heat stress also triggered an altered expression of MADS-box genes (Ejaz and von Korff 2017), suggesting that PRC2-mediated regulation may be sensitive to heat stress and could affect genes typically active during early stages of endosperm development (Fig. 1). Another type of epigenetic control was observed in rice plants submitted to submergence, in which H3K4me3-mediated regulation of alcohol dehydrogenase $(A D H)$ expression was regulated in a biphasic manner. First, levels of histone H3K4 changed from a di- to a tri-methylation state followed by an increase in acetylation of H3 (Tsuji et al. 2006). In contrast to H3K27me3, which is associated with gene silencing, $\mathrm{H} 3 \mathrm{~K} 4 \mathrm{me} 3$ typically correlates with transcriptional activation (Zhang et al. 2007). A global DNA methylation study during seed development in rice showed that the expression of genes responding to the growth hormone auxin and the stress hormone $\mathrm{ABA}$ was controlled by DNA methylation (Xing et al. 2015). Recently, this has also been described in barley (Surdonja et al. 2017), indicating that the cellularization process of cereal endosperm could be especially stress-sensitive. Therefore, it was suggested that DNA methylation controls ABA levels and thus promotes endosperm cellularization in cereals. Alteration in embryo and endosperm formation during stress could thus be due to a combined alteration of PRC2 regulation and hormonal imbalance, resulting, as a consequence, in alteration in gene expression. In summary, the combination of hormonal and epigenetic regulation through DNA methylation as well as H3K27me3 and $\mathrm{H} 3 \mathrm{~K} 4 \mathrm{me} 3$ methylation appears critical during early seed development and thus might be especially sensitive to environmental stresses. 


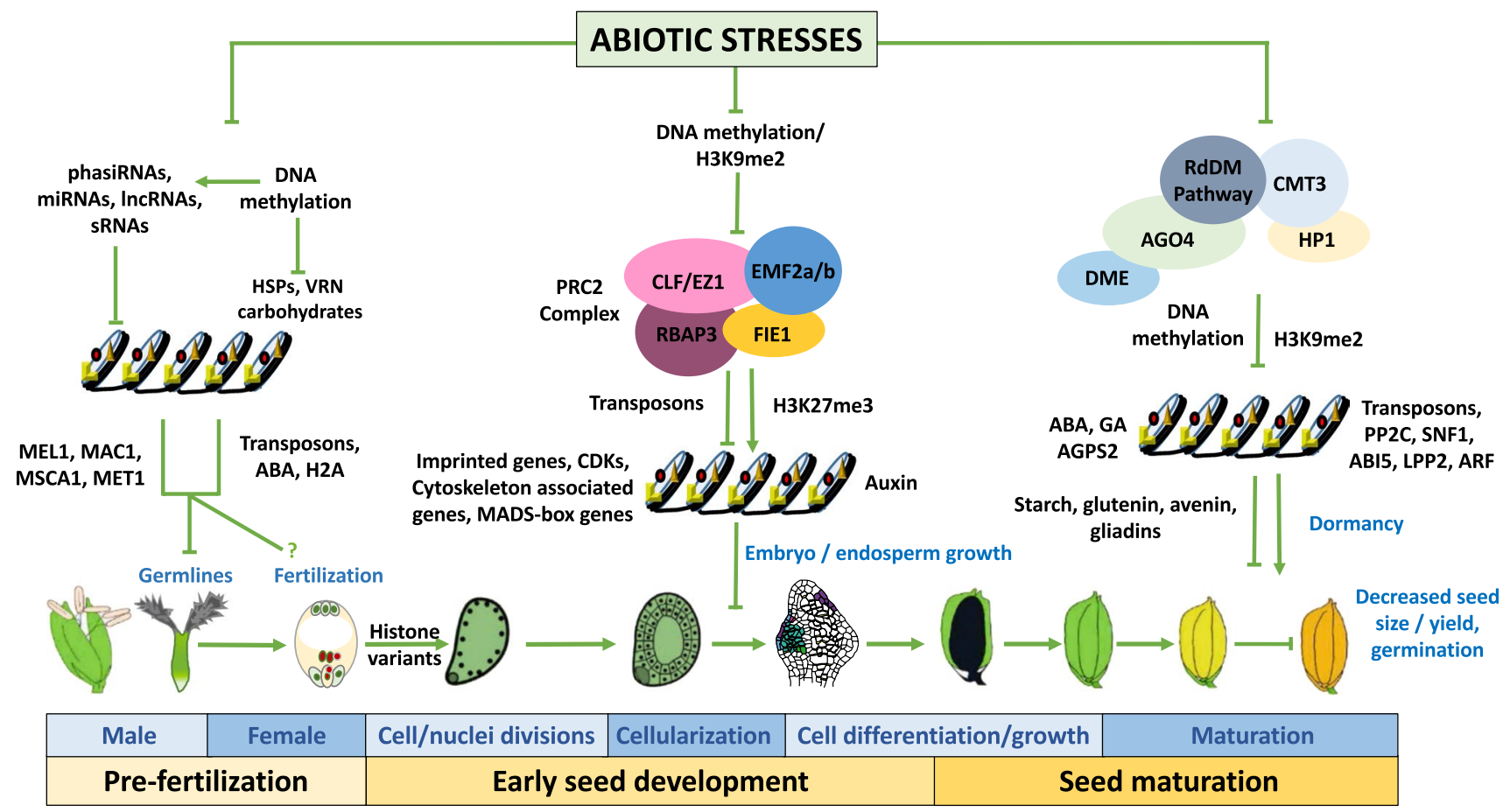

Fig. 1 Integrative model of the effects of abiotic stresses on the epigenetic status of cereals during reproductive development. Pre-fertilization, early seed development and maturation events in response

Reactivation of TEs can occur under certain situations including environmental conditions or after genome rearrangements (Vicient and Casacuberta 2017). In rice, heat stress during early seed development triggered genomewide alterations including reactivation of transposable elements by a decrease in DNA methylation at noncoding regions (Chen et al. 2016). This particular activation was more accentuated with the severity of the stress indicating a temperature-sensitive quantitative response (Chen et al. 2016). Elevated rates of retrotransposon movement creating new insertional polymorphisms, which are associated with deleterious effects, were indeed induced by microclimate changes in barley and rice (Kalendar et al. 2000; Naito et al. 2006). Therefore, mis-regulation of DNA methylation by increased temperatures results in changes in the epigenetic state of the genomes, which likely cause a significant rearrangement of TE activity.

\section{Abiotic stresses during seed maturation}

Seed maturation is a key stage during seed development in which fundamental processes including embryo growth and enlargement terminate, while mechanisms leading to accumulation of storage products, desiccation tolerance and seed dormancy are activated. In heat-sensitive wheat varieties, to stresses are described. The main epigenetic alterations and corresponding molecular players are indicated. See text for detailed explanations

it was shown that heat stress applied during the seed maturation stage strongly affected seed vigor and germination rate by changing, for example, the amount of storage products and hormones (Hasan et al. 2013). In contrast, a 24-h period of moderate heat stress in rice during the same stage generated seeds that exhibited better and faster germination rates compared to non-stressed seeds. More detailed characterization of heat-stressed seeds showed that a short-term period of stress resulted in higher hormonal status of gibberellic acid (GA) and ABA, as well as of total starch content. These findings indicate that a 24 -h post-zygotic heat stress potentially primes embryos of some lines to germinate faster, possibly through an altered sensitivity to ABA and increased resource allocation. Nonetheless, any longer period of heat stress was detrimental for seed establishment and germination (Begcy and Walia 2015b). Additional evidence also indicates that active DNA demethylation triggered by stresses altered regulation of ABA synthesis genes resulting in higher ABA levels (Kakumanu et al. 2012; Xing et al. 2015). A similar response was observed in heatstressed rice and drought-stressed wheat seeds, in which a subset of genes associated with cytoskeleton organization and hormone pathways were mis-regulated. Notably, strong transcriptional repression was also observed in genes associated with wheat storage proteins such as gliadins, glutenins, and avenins (Begcy and Walia 2015a, b; Chen et al. 2016). 
Notably, both the aforementioned pathways have been shown to be controlled by PRC2 (Kapazoglou et al. 2010; Tonosaki and Kinoshita 2015), indicating that likely PRC2-mediated regulation also plays an important role during seed maturation under drought stress (Fig. 1).

In barley, a DNA glycosylase closely related to Demeter (DME) required for maternal allele demethylation and imprinting in the endosperm was reported to be involved in responses to stress. In a drought-tolerant barley variety, increased $H v D M E$ expression was correlated with enhanced tolerance compared with a drought-sensitive variety. Variation in tolerance between varieties was partially explained by different levels of DNA methylation found in specific regions of the promoter and gene body of $H v D M E$ (Kapazoglou et al. 2013). Additionally, the presence of a Copia retrotransposon element within the $3^{\prime}$ downstream region of $H v D M E$ might have contributed to increased tolerance, although the detailed molecular mechanisms remained unclear. Similarly, enhanced tolerance to abiotic stresses has also been described recently in common wheat by a miniature inverted-repeat transposable elements (MITEs) insertion into the 3'-UTR of HSP16.9 affecting its transcription rate (Li et al. 2014; Makarevitch et al. 2015). This indicates that transposon activity might have significantly contributed to the establishment of genetic responses to abiotic stress.

A recent study performed during rice seed development detected a strong increase in acetylation levels of proteins during seed differentiation and maturation (Wang et al. 2017). Most acetylated proteins were associated with processes involved in starch and sucrose metabolism, glycolysis/gluconeogenesis, and the tricarboxylic acid (TCA) cycle. This pattern of acetylation coincides with the starch biosynthesis phase in rice, which begins at 5 DAF (days after fertilization) and continues through seed maturation. During/ after abiotic stress, a high induction of acetylation was also found at a genome-wide context at histone proteins. During stress conditions, the promoter region of cell cycle genes showed hyper-acetylation at specific lysine sites at $\mathrm{H} 3$ and $\mathrm{H} 4$ tails in maize, which correlated with prolonged cell cycle duration and an inhibitory effect of growth and development (Zhao et al. 2014). However, one cannot exclude the possibility that increased acetylation of cell cycle genes might be an indirect effect of abiotic stresses. Thus, it is important to highlight that besides the known role of DNA methylation, histone acetylation also controls important transition phases during seed development in cereals and thus opens the door for further studies on how acetylation and other posttranscriptional modifications are altered and affected by abiotic stresses during seed development.

Additionally, RdDM pathways have been shown to regulate many developmental processes including seed maturation in cereals (Lanciano and Mirouze 2017; Liu et al. 2016). Methylated histones recruit a specific DNA methyltransferase, chromomethylase 3 (CMT3), through physical interaction with heterochromatin protein 1 (HP1) to the DNA and trigger cytosine methylation (Dangwal et al. 2014; Smallwood et al. 2007). In barley and wheat, AGO proteins, which participate in gene silencing through RdDM pathways and which are components of the RNA-induced silencing complex (RISC), were shown to regulate seed maturation and dormancy (Singh and Singh 2012; Singh et al. 2014). When barley plants were submitted to terminal stress during grain filling, increased DNA methylation was observed, for example, in the promoter region of the Cytokinin-Oxidase 2.1 (CKX2.1) gene, which is a target of the RdDM pathway (Surdonja et al. 2017). Moreover, it was reported that dormancy was reduced at both increased temperatures and water deficit during seed maturation (Begcy and Walia 2015b; Singh et al. 2014). Regulation of dormancy is associated with a decrease in seed sensitivity to signaling molecules including hormones such as ABA and auxin (IAA). Their biosynthesis and readout were shown to be affected as several hormone-related genes encoding, for instance, protein phosphatase 2C (PP2C), SNF1-related protein kinase 2 (SNF1), ABA insensitive 5 (ABI5), lipid phosphate phosphatase 2 (LPP2), and auxin response factors (ARFs), which are transcriptionally repressed during stress exposure, were mis-regulated (Liu et al. 2013; Yu et al. 2016). It is thus likely that initially RdDM pathways are affected, which then cause mis-regulation of the abovementioned genes. However, this correlation leading to shortening of dormancy under stress conditions requires further experimental evidence.

\section{Conclusions and perspectives}

Epigenetic mechanisms controlling reproductive development have been shown in the past decade as pivotal regulators of stress responses in cereals. Development and function of female and especially male gametophytes appear to be especially susceptible to abiotic stresses. DNA methylation and small regulatory RNAs including phasiRNAs, lncRNAs, and miRNAs have been shown as repressors of germline initiator genes. Mis-regulation of germline-specific genes during abiotic stresses seems to be a consequence of the lack of the aforementioned epigenetic regulators (Fig. 1).

It is still unclear whether the fertilization process itself is affected by stresses and if so, which epigenetic components are the main targets. However, since histone variants are exchanged during zygotic gene activation at non-stress conditions and DNA methylation of imprinted genes is active immediately after fertilization, we speculate that this stage is also affected by abiotic stresses. Proper activity of the PRC2 complex is very critical for seed formation during early stages involved in cell/nuclei divisions, 
endosperm cellularization, and embryo patterning (Fig. 1). Abiotic stresses such as drought and heat stress affect the expression of PRC2 complex members by removing their H3 K9me3 epigenetic marks. DNA methylation of developmental regulator genes including MADS-box genes repressed by PRC2 under non-stress conditions is reduced by abiotic stresses leading to a shift in their transcriptional expression and thus to seed malformation and/or a delay in development (Fig. 1). During seed maturation, hormone levels of ABA, GA, and IAA are controlled by DNA methylation. Changes in their levels under stress conditions strongly impact proper seed development. Together with epigenetic factors including the RdDM pathway, which recruits AGO, CMT3, DME, and other proteins, hormone imbalance represents a key regulator of stress responses.

These above-described findings now provide exciting prospects since a large number of these processes are crucial for maintenance of yield and reproductive success under abiotic stress conditions. In conclusion, even though plants are exposed to abiotic stresses throughout their life cycle, reproductive development is more vulnerable to abiotic stresses compared to vegetative developmental stages as stress may terminate development and lead to complete sterility. The systematic study of epigenetic regulatory mechanisms under abiotic stress conditions during reproductive development needs to be extended and approached under field conditions, since multiple stresses are frequently coexistent. Inheritable epigenetic changes such as small regulatory mechanisms, histone variants, and DNA methylation are also unexplored in cereals in a trans-generational memory context, since these epigenetic variations might improve stress resilience in the offspring.

Finally, although new tissue- and cell-specific methodologies including fluorescence-activated cell sorting, ATACseq, and methylome sequencing (e.g., Begcy and Dresselhaus 2017; Borges et al. 2012; Buenrostro et al. 2015; Farlik et al. 2015) permit to study reproductive development in spatiotemporal detail in response to stresses, some key developmental processes such as embryo sac development and fertilization still remain largely unexplored due to technical difficulties associated with their isolation and observation. Further advances in the sensitivity of methods allowing single cell genome sequencing, interactome, proteome, and metabolome studies as well as gene-editing technologies, which work well for cereals, will facilitate systematic and comprehensive genome-wide studies and the identification of new candidate genes controlling epigenetic responses in cereal to environmental stresses.

Acknowledgements We thank Mike Grene for manuscript editing and proofreading. This work was supported by the BayKlimaFit program of the Bavarian State Ministry of the Environment and Consumer Protection (Grant No. 810100) to T.D.

\section{Compliance with ethical standard}

Conflict of interest The authors declare that they have no conflict of competing interest.

Open Access This article is distributed under the terms of the Creative Commons Attribution 4.0 International License (http://creativeco mmons.org/licenses/by/4.0/), which permits unrestricted use, distribution, and reproduction in any medium, provided you give appropriate credit to the original author(s) and the source, provide a link to the Creative Commons license, and indicate if changes were made.

\section{References}

Abiko M, Akibayashi K, Sakata T, Kimura M, Kihara M, Itoh K, Asamizu E, Sato S, Takahashi H, Higashitani A (2005) Hightemperature induction of male sterility during barley (Hordeum vulgare $\mathrm{L}$.) anther development is mediated by transcriptional inhibition. Sex Plant Reprod 18:91-100. https://doi.org/10.1007/ s00497-005-0004-2

Andersen MN, Asch F, Wu Y, Jensen CR, Naested H, Mogensen VO, Koch KE (2002) Soluble invertase expression is an early target of drought stress during the critical, abortion-sensitive phase of young ovary development in maize. Plant Physiol 130:591-604. https://doi.org/10.1104/pp.005637

Anderson SN, Johnson CS, Chesnut J, Jones DS, Khanday I, Woodhouse M, Li C, Conrad LJ, Russell SD, Sundaresan V (2017) The zygotic transition is initiated in unicellular plant zygotes with asymmetric activation of parental genomes. Dev Cell 43:349358. https://doi.org/10.1016/j.devcel.2017.10.005

Asch F, Andersen MN, Jensen CR, Mogensen VO (2001) Ovary abscisic acid concentration does not induce kernel abortion in fieldgrown maize subjected to drought. Eur J Agron 15:119-129. https://doi.org/10.1016/S1161-0301(01)00101-0

Asensi-Fabado MA, Amtmann A, Perrella G (2017) Plant responses to abiotic stress: the chromatin context of transcriptional regulation. BBA Gene Regul Mech 1860:106-122. https://doi.org/10.1016/j. bbagrm.2016.07.015

Barnabas B, Jäger K, Feher A (2008) The effect of drought and heat stress on reproductive processes in cereals. Plant Cell Environ 31:11-38. https://doi.org/10.1111/j.1365-3040.2007.01727.x

Baroux C, Grossniklaus U (2015) The maternal-to-zygotic transition in flowering plants: evidence, mechanisms, and plasticity. Curr Top Dev Biol 113:351-371. https://doi.org/10.1016/ bs.ctdb.2015.06.005

Bartels D, Sunkar R (2005) Drought and salt tolerance in plants. Crit Rev Plant Sci 24:23-58. https://doi.org/10.1080/0735268059 0910410

Basu S, Ramegowda V, Kumar A, Pereira A (2016) Plant adaptation to drought stress. F1000Research 5:1554. https://doi.org/10.12688 /f1000research.7678.1

Begcy K, Dresselhaus T (2017) Tracking maize pollen development by the leaf collar method. Plant Reprod 30:171-178. https://doi. org/10.1007/s00497-017-0311-4

Begcy K, Walia H (2015a) Drought stress delays endosperm development and misregulates genes associated with cytoskeleton organization and grain quality proteins in developing wheat seeds. Plant Sci 240:109-119. https://doi.org/10.1016/j.plant sci.2015.08.024

Begcy K, Walia H (2015b) Transgenerational influence of heat stress during early seed development on rice seeds. In: Dissertation: early seed development responses in cereals under environmental 
stresses. ETD collection for University of Nebraska, Lincoln, pp 1-120. https://digitalcommons.unl.edu/dissertations/AAI37 39271. Accessed 1 Nov 2017

Begcy K, Mariano ED, Mattiello L, Nunes AV, Mazzafera P, Maia IG, Menossi M (2011) An Arabidopsis mitochondrial uncoupling protein confers tolerance to drought and salt stress in transgenic tobacco plants. PLoS ONE 6:e23776. https://doi.org/10.1371/ journal.pone.0023776

Bleckmann A, Alter S, Dresselhaus T (2014) The beginning of a seed: regulatory mechanisms of double fertilization. Front Plant Sci 5:452. https://doi.org/10.3389/fpls.2014.00452

Borges F, Gardner R, Lopes T, Calarco JP, Boavida LC, Slotkin RK, Martienssen RA, Becker JD (2012) FACS-based purification of Arabidopsis microspores, sperm cells and vegetative nuclei. Plant Methods 8:44. https://doi.org/10.1186/1746-4811-8-44

Buenrostro JD, Wu B, Chang HY, Greenleaf WJ (2015) ATAC-seq: a method for assaying chromatin accessibility genome-wide. Curr Protoc Mol Biol 109:1-9. https://doi.org/10.1002/04711 42727.mb2129s 109

Chaubal R, Anderson JR, Trimnell MR, Fox TW, Albertsen MC, Bedinger P (2003) The transformation of anthers in the msca1 mutant of maize. Planta 216:778-788. https://doi.org/10.1007/ s00425-002-0929-8

Chen C, Begcy K, Liu K, Folsom JJ, Wang Z, Zhang C, Walia H (2016) Heat stress yields a unique MADS box transcription factor in determining seed size and thermal sensitivity. Plant Physiol 171:606-622. https://doi.org/10.1104/pp.15.01992

Chen J, Strieder N, Krohn NG, Cyprys P, Sprunck S, Engelmann JC, Dresselhaus T (2017) Zygotic genome activation occurs shortly after fertilization in maize. Plant Cell 29:2106-2125. https:// doi.org/10.1105/tpc.17.00099

Chinnusamy V, Gong Z, Zhu JK (2008) Abscisic acid-mediated epigenetic processes in plant development and stress responses. J Integr Plant Biol 50:1187-1195. https://doi.org/10.111 1/j.1744-7909.2008.00727.x

Cui X, Cao X (2014) Epigenetic regulation and functional exaptation of transposable elements in higher plants. Curr Opin Plant Biol 21:83-88. https://doi.org/10.1016/j.pbi.2014.07.001

Damptey HB, Aspinall D (1976) Water deficit and inflorescence development in Zea mays L. Ann Bot 40:23-35. https://doi. org/10.1093/oxfordjournals.aob.a085111

Damptey HB, Coombe BG, Aspinall D (1978) Apical dominance, water deficit and axillary inflorescence growth in Zea mays: the role of abscisic-acid. Ann Bot 42:1447-1458. https://doi. org/10.1093/oxfordjournals.aob.a085592

Dangwal M, Kapoor S, Kapoor M (2014) The PpCMT chromomethylase affects cell growth and interacts with the homolog of LIKE HETEROCHROMATIN PROTEIN 1 in the moss Physcomitrella patens. Plant J 77:589-603. https://doi.org/10.1111/ tpj. 12406

Dante RA, Larkins BA, Sabelli PA (2014) Cell cycle control and seed development. Front Plant Sci 5:493. https://doi.org/10.3389/ fpls.2014.00493

Dennis ES, Peacock WJ (2009) Vernalization in cereals. J Biol 8:57. https://doi.org/10.1186/jbiol156

Diallo AO, Ali-Benali MA, Badawi M, Houde M, Sarhan F (2012) Expression of vernalization responsive genes in wheat is associated with histone $\mathrm{H} 3$ trimethylation. Mol Genet Genom 287:575590. https://doi.org/10.1007/s00438-012-0701-0

Ding JH, Lu Q, Ouyang YD, Mao HL, Zhang PB, Yao JL, Xu CG, Li $\mathrm{XH}$, Xiao JH, Zhang QF (2012) A long noncoding RNA regulates photoperiod-sensitive male sterility, an essential component of hybrid rice. Proc Natl Acad Sci USA 109:2654-2659. https:// doi.org/10.1073/pnas.1121374109
Dong XJ, Weng ZP (2013) The correlation between histone modifications and gene expression. Epigenomics 5:113-116. https://doi. org/10.2217/epi.13.13

Dresselhaus T, Sprunck S, Wessel GM (2016) Fertilization mechanisms in flowering plants. Curr Biol 26:R125-R139. https://doi. org/10.1016/j.cub.2015.12.032

Dukowic-Schulze S, Sundararajan A, Ramaraj T, Kianian S, Pawlowski WP, Mudge J, Chen CB (2016) Novel meiotic miRNAs and indications for a role of phasiRNAs in meiosis. Front Plant Sci 7:762. https://doi.org/10.3389/fpls.2016.00762

Dupuis I, Dumas C (1990) Influence of temperature stress on in vitro fertilization and heat shock protein synthesis in maize (Zea mays L.) reproductive tissues. Plant Physiol 94:665-670. https://doi. org/10.1104/pp.94.2.665

Ejaz M, von Korff M (2017) The genetic control of reproductive development under high ambient temperature. Plant Physiol 173:294306. https://doi.org/10.1104/pp.16.01275

Fahad S, Bajwa AA, Nazir U, Anjum SA, Farooq A, Zohaib A, Sadia S, Nasim W, Adkins S, Saud S, Ihsan MZ, Alharby H, Wu C, Wang D, Huang J (2017) Crop production under drought and heat stress: plant responses and management options. Front Plant Sci 8:1147. https://doi.org/10.3389/fpls.2017.01147

Fan Y, Zhang Q (2018) Genetic and molecular characterization of photoperiod and thermo-sensitive male sterility in rice. Plant Reprod 31:3-14. https://doi.org/10.1007/s00497-017-0310-5

Farlik M, Sheffield NC, Nuzzo A, Datlinger P, Schonegger A, Klughammer J, Bock C (2015) Single-cell DNA methylome sequencing and bioinformatic inference of epigenomic cell-state dynamics. Cell Rep 10:1386-1397. https://doi.org/10.1016/j.celre p.2015.02.001

Fei Q, Xia R, Meyers BC (2013) Phased, secondary, small interfering RNAs in posttranscriptional regulatory networks. Plant Cell 25:2400-2415. https://doi.org/10.1105/tpc.113.114652

Fei Q, Yang L, Liang WQ, Zhang DB, Meyers BC (2016) Dynamic changes of small RNAs in rice spikelet development reveal specialized reproductive phasiRNA pathways. J Exp Bot 67:60376049. https://doi.org/10.1093/jxb/erw361

Ferreira THS, Tsunada MS, Bassi D, Araujo P, Mattiello L, Guidelli GV, Righetto GL, Goncalves VR, Lakshmanan P, Menossi M (2017) Sugarcane water stress tolerance mechanisms and its implications on developing biotechnology solutions. Front Plant Sci 8:1077. https://doi.org/10.3389/fpls.2017.01077

Folsom JJ, Begcy K, Hao X, Wang D, Walia H (2014) Rice fertilization-independent endosperm1 regulates seed size under heat stress by controlling early endosperm development. Plant Physiol 165:238-248. https://doi.org/10.1104/pp.113.232413

Fu W, Wu K, Duan J (2007) Sequence and expression analysis of histone deacetylases in rice. Biochem Biophys Res Commun 356:843-850. https://doi.org/10.1016/j.bbrc.2007.03.010

Fujita Y, Yoshida T, Yamaguchi-Shinozaki K (2013) Pivotal role of the AREB/ABF-SnRK2 pathway in ABRE-mediated transcription in response to osmotic stress in plants. Physiol Plant 147:15-27. https://doi.org/10.1111/j.1399-3054.2012.01635.x

Gorovits R, Czosnek H (2017) The involvement of heat shock proteins in the establishment of tomato yellow leaf curl virus infection. Front Plant Sci 8:355. https://doi.org/10.3389/fpls.2017.00355

Grimanelli D, Perotti E, Ramirez J, Leblanc O (2005) Timing of the maternal-to-zygotic transition during early seed development in maize. Plant Cell 17:1061-1072. https://doi.org/10.1105/ tpc.104.029819

Hands P, Kourmpetli S, Sharples D, Harris RG, Drea S (2012) Analysis of grain characters in temperate grasses reveals distinctive patterns of endosperm organization associated with grain shape. J Exp Bot 63:6253-6266. https://doi.org/10.1093/jxb/ers281

Hasan M, Ahmed J, Hossain T, Mian M, Haque M (2013) Evaluation of the physiological quality of wheat seed as influenced by high 
parent plant growth temperature. J Crop Sci Biotechnol 16:69. https://doi.org/10.1007/s12892-010-0056-1

He GM, Zhu XP, Elling AA, Chen LB, Wang XF, Guo L, Liang MZ, He H, Zhang HY, Chen FF, Qi YJ, Chen RS, Deng XW (2010) Global epigenetic and transcriptional trends among two rice subspecies and their reciprocal hybrids. Plant Cell 22:17-33. https ://doi.org/10.1105/tpc.109.072041

He M, Zhu C, Dong K, Zhang T, Cheng Z, Li J, Yan Y (2015) Comparative proteome analysis of embryo and endosperm reveals central differential expression proteins involved in wheat seed germination. BMC Plant Biol 15:97. https://doi.org/10.1186/ s12870-015-0471-Z

Huh JH, Bauer MJ, Hsieh TF, Fischer R (2007) Endosperm gene imprinting and seed development. Curr Opin Genet Dev 17:480-485. https://doi.org/10.1016/j.gde.2007.08.011

Hyun Y, Richter R, Coupland G (2017) Competence to flower: agecontrolled sensitivity to environmental cues. Plant Physiol 173:36-46. https://doi.org/10.1104/pp.16.01523

Ji X, Dong BD, Shiran B, Talbot MJ, Edlington JE, Hughes T, White RG, Gubler F, Dolferus R (2011) Control of abscisic acid catabolism and abscisic acid homeostasis is important for reproductive stage stress tolerance in cereals. Plant Physiol 156:647-662. https://doi.org/10.1104/pp.111.176164

Jin Y, Yang H, Wei Z, Ma H, Ge X (2013) Rice male development under drought stress: phenotypic changes and stage-dependent transcriptomic reprogramming. Mol Plant 6:1630-1645. https ://doi.org/10.1093/mp/sst067

Kakumanu A, Ambavaram MM, Klumas C, Krishnan A, Batlang U, Myers E, Grene R, Pereira A (2012) Effects of drought on gene expression in maize reproductive and leaf meristem tissue revealed by RNA-Seq. Plant Physiol 160:846-867. https://doi. org/10.1104/pp.112.200444

Kalendar R, Tanskanen J, Immonen S, Nevo E, Schulman AH (2000) Genome evolution of wild barley (Hordeum spontaneum) by BARE-1 retrotransposon dynamics in response to sharp microclimatic divergence. Proc Natl Acad Sci U S A 97:6603-6607. https://doi.org/10.1073/pnas.110587497

Kapazoglou A, Tondelli A, Papaefthimiou D, Ampatzidou H, Francia E, Stanca MA, Bladenopoulos K, Tsaftaris AS (2010) Epigenetic chromatin modifiers in barley: IV. The study of barley polycomb group $(\mathrm{PcG})$ genes during seed development and in response to external ABA. BMC Plant Biol 10:73. https://doi. org/10.1186/1471-2229-10-73

Kapazoglou A, Drosou V, Argiriou A, Tsaftaris AS (2013) The study of a barley epigenetic regulator, HvDME, in seed development and under drought. BMC Pant Biol 13:172. https://doi. org/10.1186/1471-2229-13-172

Karan R, DeLeon T, Biradar H, Subudhi PK (2012) Salt stress induced variation in DNA methylation pattern and its influence on gene expression in contrasting rice genotypes. PLoS ONE 7:e40203. https://doi.org/10.1371/journal.pone.0040203

Kawakatsu T, Huang SC, Jupe F, Sasaki E, Schmitz RJ, Urich MA, Castanon R, Nery JR, Barragan C, He Y, Chen H, Dubin M, Lee CR, Wang C, Bemm F, Becker C, O'Neil R, O'Malley RC, Quarless DX, Genomes C, Schork NJ, Weigel D, Nordborg M, Ecker JR (2016) Epigenomic diversity in a global collection of Arabidopsis thaliana accessions. Cell 166:492-505. https ://doi.org/10.1016/j.cell.2016.06.044

Kelliher T, Walbot V (2012) Hypoxia triggers meiotic fate acquisition in maize. Science 337:345-348. https://doi.org/10.1126/ science. 1220080

Kesten C, Menna A, Sanchez-Rodriguez C (2017) Regulation of cellulose synthesis in response to stress. Curr Opin Plant Biol 40:106-113. https://doi.org/10.1016/j.pbi.2017.08.010

Komiya R, Ohyanagi H, Niihama M, Watanabe T, Nakano M, Kurata N, Nonomura KI (2014) Rice germline-specific Argonaute
MEL1 protein binds to phasiRNAs generated from more than 700 lincRNAs. Plant J 78:385-397. https://doi.org/10.1111/ tpj. 12483

Kouzarides T (2007) Chromatin modifications and their function. Cell 128:693-705. https://doi.org/10.1016/j.cell.2007.02.005

Lamaoui M, Jemo M, Datla R, Bekkaoui F (2018) Heat and drought stresses in crops and approaches for their mitigation. Front Chem 6:26. https://doi.org/10.3389/fchem.2018.00026

Lanciano S, Mirouze M (2017) DNA methylation in rice and relevance for breeding. Epigenomes 1:10. https://doi.org/10.3390/epige nomes 1020010

Lausser A, Kliwer I, Srilunchang K, Dresselhaus T (2010) Sporophytic control of pollen tube growth and guidance in maize. J Exp Bot 61:673-682. https://doi.org/10.1093/jxb/erp330

Li XM, Sang YL, Zhao XY, Zhang XS (2013) High-throughput sequencing of small RNAs from pollen and silk and characterization of miRNAs as candidate factors involved in pollen-silk interactions in maize. PLoS ONE 8:e72852. https://doi.org/10.1371/ journal.pone.0072852

Li J, Wang Z, Peng H, Liu Z (2014) A MITE insertion into the 3'-UTR regulates the transcription of TaHSP16.9 in common wheat. Crop J 2:381-387. https://doi.org/10.1016/j.cj.2014.07.001

Li JB, Luan YS, Liu Z (2015) Overexpression of SpWRKY1 promotes resistance to Phytophthora nicotianae and tolerance to salt and drought stress in transgenic tobacco. Physiol Plant 155:248-266. https://doi.org/10.1111/ppl.12315

Liu H, Nonomura KI (2016) A wide reprogramming of histone H3 modifications during male meiosis I in rice is dependent on the Argonaute protein MEL1. J Cell Sci 129:3553-3561. https://doi. org/10.1242/jcs. 184937

Liu A, Gao F, Kanno Y, Jordan MC, Kamiya Y, Seo M, Ayele BT (2013) Regulation of wheat seed dormancy by after-ripening is mediated by specific transcriptional switches that induce changes in seed hormone metabolism and signaling. PLoS ONE 8:e56570. https://doi.org/10.1371/journal.pone.0056570

Liu X, Zhou S, Wang W, Ye Y, Zhao Y, Xu Q, Zhou C, Tan F, Cheng S, Zhou DX (2015) Regulation of histone methylation and reprogramming of gene expression in the rice inflorescence meristem. Plant Cell 27:1428-1444. https://doi.org/10.1105/tpc.15.00201

Liu H, Able AJ, Able JA (2016) SMARTER De-stressed cereal breeding. Trends Plant Sci 21:909-925. https://doi.org/10.1016/j.tplan ts.2016.07.006

Liu Q, Yang TF, Yu T, Zhang SH, Mao XX, Zhao JL, Wang XF, Dong JF, Liu B (2017) Integrating small RNA sequencing with QTL mapping for identification of miRNAs and their target genes associated with heat tolerance at the flowering stage in rice. Front Plant Sci 8:43. https://doi.org/10.3389/fpls.2017.00043

Luhua S, Hegie A, Suzuki N, Shulaev E, Luo X, Cenariu D, Ma V, Kao S, Lim J, Gunay MB, Oosumi T, Lee SC, Harper J, Cushman J, Gollery M, Girke T, Bailey-Serres J, Stevenson RA, Zhu JK, Mittler R (2013) Linking genes of unknown function with abiotic stress responses by high-throughput phenotype screening. Physiol Plant 148:322-333. https://doi.org/10.1111/ppl.12013

Makarevitch I, Waters AJ, West PT, Stitzer M, Hirsch CN, Ross-Ibarra J, Springer NM (2015) Transposable elements contribute to activation of maize genes in response to abiotic stress. PLoS Genet 11:e1004915. https://doi.org/10.1371/journal.pgen.1004915

Mattiello L, Begcy K, da Silva FR, Jorge RA, Menossi M (2014) Transcriptome analysis highlights changes in the leaves of maize plants cultivated in acidic soil containing toxic levels of $\mathrm{Al}^{(3+)}$. Mol Biol Rep 41:8107-8116. https://doi.org/10.1007/s1103 3-014-3709-1

Meng D, Dubin M, Zhang P, Osborne EJ, Stegle O, Clark RM, Nordborg M (2016) Limited contribution of DNA methylation variation to expression regulation in Arabidopsis thaliana. PLoS 
Genet 12:e1006141. https://doi.org/10.1371/journal.pgen.10061 41

Mitchell JC, Petolino JF (1988) Heat-stress effects on isolated reproductive-organs of maize. J Plant Physiol 133:625-628. https:// doi.org/10.1016/S0176-1617(88)80019-1

Müller F, Rieu I (2016) Acclimation to high temperature during pollen development. Plant Reprod 29:107-118. https://doi.org/10.1007/ s00497-016-0282-x

Naito K, Cho E, Yang G, Campbell MA, Yano K, Okumoto Y, Tanisaka T, Wessler SR (2006) Dramatic amplification of a rice transposable element during recent domestication. Proc Natl Acad Sci USA 103:17620-17625. https://doi.org/10.1073/pnas.06054 21103

Nodine MD, Bartel DP (2012) Maternal and paternal genomes contribute equally to the transcriptome of early plant embryos. Nature 482:94-97. https://doi.org/10.1038/nature10756

Nonomura K, Morohoshi A, Nakano M, Eiguchi M, Miyao A, Hirochika H, Kurata N (2007) A germ cell specific gene of the ARGONAUTE family is essential for the progression of premeiotic mitosis and meiosis during sporogenesis in rice. Plant Cell 19:2583-2594. https://doi.org/10.1105/tpc.107.053199

Oliver SN, Finnegan EJ, Dennis ES, Peacock WJ, Trevaskis B (2009) Vernalization-induced flowering in cereals is associated with changes in histone methylation at the VERNALIZATION1 gene. Proc Natl Acad Sci USA 106:8386-8391. https://doi. org/10.1073/pnas.0903566106

Parihar P, Singh S, Singh R, Singh VP, Prasad SM (2015) Effect of salinity stress on plants and its tolerance strategies: a review. Environ Sci Pollut Res Int 22:4056-4075. https://doi. org/10.1007/s11356-014-3739-1

Parish RW, Phan HA, Iacuone S, Li SF (2012) Tapetal development and abiotic stress: a centre of vulnerability. Funct Plant Biol 39:553-559. https://doi.org/10.1071/FP12090

Park CJ, Seo YS (2015) Heat Shock Proteins: a review of the molecular chaperones for plant immunity. Plant Pathol J 31:323-333. https ://doi.org/10.5423/PPJ.RW.08.2015.0150

Park K, Kim MY, Vickers M, Park JS, Hyun Y, Okamoto T, Zilberman D, Fischer RL, Feng XQ, Choi Y, Scholten S (2016) DNA demethylation is initiated in the central cells of Arabidopsis and rice. Proc Natl Acad Sci USA 113:15138-15143. https://doi. org/10.1073/pnas.1619047114

Pikaard CS, Mittelsten Scheid O (2014) Epigenetic regulation in plants. Cold Spring Harb Perspect Biol 6:a019315

Ribaut JM, Betran J, Monneveux P, Setter T (2009) Drought tolerance in maize. In: Bennetzen JL, Hake SC (eds) Handbook of maize: its biology. Springer, New York, NY. https://doi. org/10.1007/978-0-387-79418-1_16

Sabelli PA (2012) Seed development: a comparative overview on biology of morphology, physiology, and biochemistry between monocot and dicot plants. In: Agrawal G, Rakwal R (eds) Seed development: OMICS technologies toward improvement of seed quality and crop yield. Springer, Dordrecht. https://doi. org/10.1007/978-94-007-4749-4_1

Sade N, Rubio-Wilhelmi MD, Umnajkitikorn K, Blumwald E (2018) Stress-induced senescence and plant tolerance to abiotic stress. J Exp Bot 69:845-853. https://doi.org/10.1093/jxb/erx235

Singh M, Singh J (2012) Seed development-related expression of ARGONAUTE4_9 class of genes in barley: possible role in seed dormancy. Euphytica 188:123-129. https://doi.org/10.1007/ s10681-012-0624-1

Singh M, Singh S, Randhawa H, Singh J (2014) Polymorphic homoeolog of key gene of RdDM pathway, ARGONAUTE4_9 class is associated with pre-harvest sprouting in wheat (Triticum aestivum L.). PLoS ONE 9:e77009. https://doi.org/10.1371/journ al.pone.0077009
Smallwood A, Esteve PO, Pradhan S, Carey M (2007) Functional cooperation between HP1 and DNMT1 mediates gene silencing. Genes Dev 21:1169-1178. https://doi.org/10.1101/gad.1536807

Surdonja K, Eggert K, Hajirezaei M-R, Harshavardhan VT, Seiler C, von Wirén N, Sreenivasulu N, Kuhlmann M (2017) Increase of DNA methylation at the $H v C K X 2.1$ promoter by terminal drought stress in barley. Epigenomes 1:1-13. https://doi.org/10.3390/ epigenomes 1020009

Tang RS, Zheng JC, Jin ZQ, Zhang D, Huang H, Chen LG (2008) Possible correlation between high temperature-induced floret sterility and endogenous levels of IAA, GAs and ABA in rice (Oryza sativa L.). Plant Growth Regul 54:37-43. https://doi. org/10.1007/s10725-007-9225-8

Tang XM, Tao X, Wang Y, Ma DW, Li D, Yang H, Ma XR (2014) Analysis of DNA methylation of perennial ryegrass under drought using the methylation-sensitive amplification polymorphism (MSAP) technique. Mol Genet Genomics 289:10751084. https://doi.org/10.1007/s00438-014-0869-6

Tonosaki K, Kinoshita T (2015) Possible roles for polycomb repressive complex 2 in cereal endosperm. Front Plant Sci 6:144. https://doi.org/10.3389/fpls.2015.00144

Tsuji H, Saika H, Tsutsumi N, Hirai A, Nakazono M (2006) Dynamic and reversible changes in histone H3-Lys4 methylation and $\mathrm{H} 3$ acetylation occurring at submergence-inducible genes in rice. Plant Cell Physiol 47:995-1003. https://doi.org/10.1093/ $\mathrm{pcp} / \mathrm{pcj} 072$

Vicient CM, Casacuberta JM (2017) Impact of transposable elements on polyploid plant genomes. Ann Bot 120:195-207. https://doi. org/10.1093/aob/mcx078

Wang CJ, Nan GL, Kelliher T, Timofejeva L, Vernoud V, Golubovskaya IN, Harper L, Egger R, Walbot V, Cande WZ (2012) Maize multiple archesporial cells 1 (mac1), an ortholog of rice TDL1A, modulates cell proliferation and identity in early anther development. Development 139:2594-2603. https://doi. org/10.1242/dev.077891

Wang Y, Li HX, Sun QX, Yao YY (2016) Characterization of small RNAs derived from tRNAs, rRNAs and snoRNAs and their response to heat stress in wheat seedlings. PLoS ONE 11:e0150933. https://doi.org/10.1371/journal.pone.0150933

Wang Y, Hou Y, Qiu J, Li Z, Zhao J, Tong X, Zhang J (2017) A quantitative acetylomic analysis of early seed development in rice (Oryza sativa L.). Int J Mol Sci 18:1376. https://doi. org/10.3390/ijms 18071376

Wong MM, Chong GL, Verslues PE (2017) Epigenetics and RNA processing: connections to drought, salt, and ABA? Methods Mol Biol 1631:3-21. https://doi.org/10.1007/978-1-4939-7136-7_1

Xia H, Huang W, Xiong J, Yan S, Tao T, Li J, Wu J, Luo L (2017) Differentially methylated epiloci generated from numerous genotypes of contrasting tolerances are associated with osmotic-tolerance in rice seedlings. Front Plant Sci 8:11. https ://doi.org/10.3389/fpls.2017.00011

Xing MQ, Zhang YJ, Zhou SR, Hu WY, Wu XT, Ye YJ, Wu XX, Xiao YP, Li X, Xue HW (2015) Global analysis reveals the crucial roles of DNA methylation during rice seed development. Plant Physiol 168:1417-1432. https://doi.org/10.1104/ pp. 15.00414

Yang JC, Zhang JH, Wang ZQ, Zhu QS, Wang W (2001) Hormonal changes in the grains of rice subjected to water stress during grain filling. Plant Physiol 127:315-323. https://doi.org/10.1104/ pp.127.1.315

Yi G, Lauter AM, Scott MP, Becraft PW (2011) The thick aleurone1 mutant defines a negative regulation of maize aleurone cell fate that functions downstream of defective kernel1. Plant Physiol 156:1826-1836. https://doi.org/10.1104/pp.111.177725

Yu YL, Zhen SM, Wang S, Wang YP, Cao H, Zhang YZ, Li JR, Yan YM (2016) Comparative transcriptome analysis of wheat embryo 
and endosperm responses to $\mathrm{ABA}$ and $\mathrm{H}_{2} \mathrm{O}_{2}$ stresses during seed germination. BMC Genom 17:97. https://doi.org/10.1186/s1286 4-016-2416-9

Zemach A, Kim MY, Silva P, Rodrigues JA, Dotson B, Brooks MD, Zilberman D (2010) Local DNA hypomethylation activates genes in rice endosperm. Proc Natl Acad Sci USA 107:18729-18734. https://doi.org/10.1073/pnas.1009695107

Zhai JX, Zhang H, Arikit S, Huang K, Nan GL, Walbot V, Meyers BC (2015) Spatiotemporally dynamic, cell-type-dependent premeiotic and meiotic phasiRNAs in maize anthers. Proc Natl Acad Sci USA 112:3146-3151. https://doi.org/10.1073/pnas.1418918112

Zhang K, Sridhar VV, Zhu J, Kapoor A, Zhu JK (2007) Distinctive core histone post-translational modification patterns in Arabidopsis thaliana. PLoS ONE 2:e1210. https://doi.org/10.1371/ journal.pone. 0001210

Zhang N, Zhang HJ, Sun QQ, Cao YY, Li X, Zhao B, Wu P, Guo YD (2017) Proteomic analysis reveals a role of melatonin in promoting cucumber seed germination under high salinity by regulating energy production. Sci Rep 7:503. https://doi.org/10.1038/s4159 8-017-00566-1

Zhao P, Sun MX (2015) The maternal-to-zygotic transition in higher plants: available approaches, critical limitations, and technical requirements. Curr Top Dev Biol 113:373-398. https://doi. org/10.1016/bs.ctdb.2015.06.006

Zhao BT, Ge LF, Liang RQ, Li W, Ruan KC, Lin HX, Jin YX (2009) Members of miR-169 family are induced by high salinity and transiently inhibit the NF-YA transcription factor. BMC Mol Biol 10:29. https://doi.org/10.1186/1471-2199-10-29

Zhao L, Wang P, Hou HL, Zhang H, Wang YP, Yan SH, Huang Y, Li H, Tan JJ, Hu A, Gao F, Zhang Q, Li YN, Zhou H, Zhang W, Li LJ (2014) Transcriptional regulation of cell cycle genes in response to abiotic stresses correlates with dynamic changes in histone modifications in maize. PLoS ONE 9:e106070. https:// doi.org/10.1371/journal.pone.0106070

Zhao P, Begcy K, Dresselhaus T, Sun MX (2017) Does early embryogenesis in eudicots and monocots involve the same mechanism and molecular players? Plant Physiol 173:130-142. https://doi. org/10.1104/pp.16.01406

Zhou H, Liu QJ, Li J, Jiang DG, Zhou LY, Wu P, Lu S, Li F, Zhu LY, Liu ZL, Chen LT, Liu YG, Zhuang CX (2012) Photoperiod- and thermo-sensitive genic male sterility in rice are caused by a point mutation in a novel noncoding RNA that produces a small RNA. Cell Res 22:649-660. https://doi.org/10.1038/cr.2012.28

Zhou LZ, Juranic M, Dresselhaus T (2017) Germline development and fertilization mechanisms in maize. Mol Plant 10:389-401. https ://doi.org/10.1016/j.molp.2017.01.012

Zhuang YL, Ren GJ, Zhu Y, Hou GH, Qu X, Li ZX, Yue GD, Zhang JR (2008) Transcriptional profiles of immature ears and tassels in maize at early stage of water stress. Biol Plant 52:754-758. https://doi.org/10.1007/s10535-008-0146-9 